\title{
Enhancement of hepatocyte growth factor (scatter factor) production by human gingival fibroblasts in culture stimulated with Porphyromonas gingivalis fimbriae
}

\author{
A. SUGIYAMA*\&, T. OGAWA $\dagger$, Y. DAIKUHARA $:$ and H. TAKADA* \\ * Department of Microbiology and Immunology, Tohoku University School of Dentistry, Sendai 980-8575, \\ $\uparrow$ Department of Oral Microbiology, Asahi University School of Dentistry, Gifu 501-0296 and \$Department of \\ Biochemistry, Kagoshima University Dental School, Kagoshima 890-8544, Japan
}

\begin{abstract}
Hepatocyte growth factor (HGF), also known as scatter factor (SF), is a motogen, mitogen and morphogen produced by mesenchymal cells that mainly acts on epithelial cells and is involved in osteoclast stimulation. This study examined the possible enhanced production of HGF/SF by human gingival fibroblasts upon stimulation with killed cells of Porphyromonas gingivalis strain 381 and its representative bioactive cellular components, fimbriae and lipopolysaccharide (LPS). $P$. gingivalis whole cells enhanced the production of HGF/SF detected by ELISA in culture supernates of the fibroblasts. Fimbriae prepared from $P$. gingivalis exhibited powerful HGF/SF-inducing activity in a concentration-dependent manner, with peak activity observed at $100-200 \mu \mathrm{g} / \mathrm{ml}$. The fimbriae-induced HGF/SF mRNA expression by the cells was also detected by reverse transcription-PCR. $P$. gingivalis LPS exhibited weak HGF/SF-inducing activity. The study also examined the HGF/SF-inducing activity of seven synthetic peptides corresponding to the segments of $P$. gingivalis fimbrial subunit protein. The peptides of residues 282-301 and 302-321, which exhibited antagonistic effects against $P$. gingivalis fimbriae-binding to human gingival fibroblasts in a previous study, showed weak activity, whereas other non-antagonistic peptides showed no significant activity. These findings indicated that $P$. gingivalis fimbriae enhanced production of HGF/SF by human gingival fibroblasts, whereas synthetic peptide segments of fimbrial subunit protein were not sufficient to exert the activity.
\end{abstract}

\section{Introduction}

Hepatocyte growth factor (HGF) was first purified from the plasma of patients with fulminant hepatic failure as a potent mitogen for hepatocytes [1] and is thought to be involved in regulation of liver function [2]. HGF was eventually identified as the same protein as the scatter factor (SF) [3] purified from conditioned medium of fibroblasts in culture, which enhances the movement and induces the dissociation of epithelial colonies $[4,5]$. The receptor of HGF was demonstrated

Received 25 March 1999; revised manuscript received 17 June 1999; accepted 14 Aug. 1999.

Corresponding author: Professor H. Takada (e-mail: dent-ht @mail.cc.tohoku.ac.jp).

§Present address: Department of Preventive Dentistry, School of Dentistry, University of Tokushima, Tokushima 770-8504, Japan. to be the product of the c-met protooncogene $[6,7]$, and c-Met has been shown to be expressed on both epithelial and endothelial cells [5].

An earlier study demonstrated that human gingival fibroblasts released $\mathrm{HGF} / \mathrm{SF}$ upon stimulation with interleukin (IL) $-1 \alpha / \beta$ and tumour necrosis factor (TNF)- $\alpha$ [8]. It was then found that bacterial cell-surface components such as lipoteichoic acid (LTA) from various gram-positive bacteria and a glycoprotein fraction (PGP) from the periodontitis-associated bacterium Prevotella intermedia enhanced the production of $\mathrm{HGF} / \mathrm{SF}$ by human gingival fibroblasts, whereas lipopolysaccharides (LPS) examined to date - including that of $P r$. intermedia - lacked the activity $[9,10]$. It was also found that recombinant human $\mathrm{HGF} / \mathrm{SF}$ exhibited mitogenic activity on human gingival epithelial cells (keratinocytes) [10]. HGF/SF has been implicated in bone resorption through the stimulation of osteoclasts 
$[11,12]$. Therefore, HGF/SF may be involved in both destruction and reparative phases in periodontal diseases.

Porphyromonas gingivalis has been the most intensively studied bacterium in relation to periodontal diseases [13]. Among the various cell-surface components of the bacterium, fimbriae $[14,15]$ and LPS $[16,17]$ have been the most thoroughly studied as possible virulence factors for periodontal diseases. Both components are capable of stimulating gingival fibroblasts. $P$. gingivalis fimbriae activate human gingival fibroblasts to produce cytokines such as IL-1 and IL-8 $[18,19]$. Specific binding of the fimbriae to human gingival fibroblasts was suggested [18] and the binding regions within the fimbrial subunit protein, fimbrillin, were demonstrated with synthetic peptides [20] (Table 1). It has been shown that LPS of $P$. gingivalis stimulates human gingival fibroblasts to produce various inflammatory cytokines such as IL-1, IL-6 and IL-8 under experimental conditions, whereas common LPS from Enterobacteriaceae such as Salmonella spp. and Escherichia coli did not exhibit such activity $[21,22]$. A recent study observed that some human gingival fibroblasts carrying membrane CD14 release IL-8 upon stimulation with common LPS and synthetic lipid A [23]. P. gingivalis LPS and lipid A also activated CD14-bearing human gingival fibroblasts, probably via membrane CD14 molecules $[19,24]$. Therefore, it is possible that fimbriae and LPS from $P$. gingivalis stimulate human gingival fibroblasts to enhance the production of $\mathrm{HGF} / \mathrm{SF}$.

In the present study, human gingival fibroblasts were stimulated with $P$. gingivalis fimbriae and LPS and the production of $\mathrm{HGF} / \mathrm{SF}$ by the cells was examined. After obtaining positive results with fimbriae, the study investigated the active regions within fimbrillin of $P$. gingivalis by examining the activities of several synthetic peptide segments of $P$. gingivalis fimbrillin.

\section{Materials and methods}

\section{Bacteria and their components}

P. gingivalis strain 381 was grown anaerobically in GAM broth (Nissui Seiyaku, Tokyo, Japan) supple- mented with haemin (Wako Pure Chemicals, Osaka, Japan) $5 \mathrm{mg} / \mathrm{L}$ and menadione (Wako) $10 \mu \mathrm{g} / \mathrm{L}$ at $37^{\circ} \mathrm{C}$ for $24 \mathrm{~h}$. The bacterial cells were collected by centrifugation and washed twice with physiological saline and once with distilled water by centrifugation, then freeze-dried. In these procedures, the anaerobic bacteria were completely killed. A fimbrial protein with a mol. wt of 41000 was isolated from freshly cultivated whole cells of $P$. gingivalis and purified chromatographically as described previously [25]. LPS was prepared by the hot phenol-water extraction method as described previously [26].

\section{Synthetic peptides and $I L-1 \alpha$}

The seven peptide segments listed in Table 1, which were based on the amino-acid sequence of native fimbrillin of $P$. gingivalis 381 deduced from the nucleotide sequence of fimbrillin, a fimbrial subunit protein proposed by Dickinson et al. [27], were synthesised as described previously [28]. These synthetic peptides were named FP381 (mm-nn): FP stands for fimbrial peptide, 381 stands for $P$. gingivalis strain 381 and mm-nn is the range of amino-acid residue numbers based on the report by Dickinson et al. [27]. The data on the antagonistic effects of these peptides against $P$. gingivalis fimbriae-binding to human gingival fibroblasts [20] are listed in Table 1. Recombinant human IL-1 $\alpha$ (rHuIL-1 $\alpha$ ) supplied by Dainippon Pharmaceutical (Osaka, Japan) was used as a positive reference stimulant throughout the study.

\section{Cells and culture conditions}

Specimens of healthy human gingival fibroblasts were obtained from 9-12-year-old patients with their parents' informed consent, as described previously [21]. The cells used in this study were confirmed to highly express membrane CD14 by flow cytometry [23]. The cells were grown and maintained in alphamodified minimal essential medium ( $\alpha$-MEM) (ICN, Amsterdam, The Netherlands) supplemented with fetal bovine serum (FBS; Gibco Laboratories, Grand Island, NY, USA) $10 \%$ and kanamycin (Meiji Seiyaku, Tokyo) $200 \mu \mathrm{g} / \mathrm{ml}$ at $37^{\circ} \mathrm{C}$ in a humidified atmosphere of $\mathrm{CO}_{2}$

Table 1. The amino acid sequences of synthetic peptides corresponding to the segments of $P$. gingivalis 381 fimbrillin

\begin{tabular}{lclc}
\hline Peptide & Position* & Amino-acid sequence* & $\begin{array}{c}\text { Antagonistic } \\
\text { activity }^{\dagger}\end{array}$ \\
\hline FP381(61-80) & $61-80$ & GKTLAEVKALTTELTAENQE & NT \\
FP381(81-101) & $81-101$ & AAGLIMTAEPKTIVLKAGKNY & - \\
FP381(142-161) & $142-161$ & NIYTFVPEKIYGLIAKKQSN & - \\
FP381(182-201) & $182-201$ & FNGAYTPANYANVPWLSRNY & - \\
FP381(216-241) & $216-241$ & ENDYSANGGTTHPTILCVYGKLQKNG & NT \\
FP381(282-301) & $282-301$ & NYTPKNKIERNHKYDIKLTI & + \\
FP381(302-321) & $302-321$ & TGPGTNNPENPITESAHLNV & + \\
\hline NT, not tested. & & \\
$*$ According to Dickinson et al. $[27]$. & \\
${ }^{\dagger}$ Inhibitory activity on $P$. gingivalis fimbriae-binding to human gingival fibroblasts (quoted from \\
Ogawa et al. [20]).
\end{tabular}


$5 \%$ in air and were used at the fifth to tenth passage in the following assays.

\section{Determination of $\mathrm{HGF} / \mathrm{SF}$ in culture supernates of fibroblasts}

Fibroblasts $\left(2 \times 10^{4}\right)$ were seeded into each well of 96well culture plates in $100 \mu 1$ of $\alpha$-MEM supplemented with FBS $10 \%$. After overnight cultivation, the cells were washed and the medium was changed to $\alpha$-MEM supplemented with FBS 1\%. The cells were then cultured in triplicate with test materials for $24 \mathrm{~h}$. Throughout this report, the concentrations of IL- $1 \alpha$ and the fimbriae are given in terms of protein, and those of whole bacterial cells, LPS and the synthetic peptides are given in terms of dry weight. The supernates were collected and stored at $-20^{\circ} \mathrm{C}$ until use. The concentrations of immunoreactive HGF/SF in culture supernates were determined in triplicate with a commercial ELISA kit (Otsuka Pharmaceutical, Tokushima, Japan), as described by Tsubouchi et al. [29]. The assays were performed according to the manufacturer's instructions.

\section{Reverse transcription (RT)-PCR}

After experimental treatments with test materials, total cellular RNA was extracted from c. $2.5 \times 10^{6}$ cells with Isogen (Nippon Gene, Tokyo, Japan) according to the manufacturer's instructions. cDNA was synthesised from the RNA solution with M-MLV reverse transcriptase (Gibco-BRL) and oligo (dT) $)_{12-18}$ primer (Gibco-BRL). To generate cDNA, $2.5 \mu \mathrm{g}$ of total RNA, $0.25 \mu \mathrm{g}$ of oligo $(\mathrm{dT})_{12-18}$ primer, First Strand Buffer (Gibco-BRL), $0.2 \mathrm{mM}$ dNTPs, 500 units of MMLV reverse transcriptase and $10 \mathrm{mM}$ dithiothreitol (Gibco-BRL) were added to a total volume of $50 \mu \mathrm{l}$. The reaction mixture was incubated for $1 \mathrm{~h}$ at $37^{\circ} \mathrm{C}$ followed by incubation for $5 \mathrm{~min}$ at $95^{\circ} \mathrm{C}$. The resulting cDNA mixture was then amplified in a solution containing Taq polymerase and the following primers specific for human $\mathrm{HGF} / \mathrm{SF}$ or GAPDH, which were prepared based on the cDNA sequences reported by Miyazawa et al. [30] and Tso et al. [31], respectively: HGF, 5'-CAAGCAATCCAGAGGTACGC-3' and 5'GTCATGTCATGCTCGTGAGG-3'; GAPDH, 5'TGAAGGTCGGAGCAACGGATTTGGT- ${ }^{\prime}$; and $5^{\prime}-$ CATGTGGGCCATGAGGTCCACCAC- $3^{\prime}$. The PCR mixture contained $5 \mu \mathrm{l}$ of cDNA mixture, $2 \mu \mathrm{l}$ of $10 \times$ PCR butter, $0.2 \mathrm{~mm}$ dNTPs, 50 pmol of each primer and Ex Taq DNA polymerase (Takara, Ohtsu, Japan) $0.1 \mu 1$ in a total volume of $20 \mu \mathrm{l}$.

Amplification was performed in a PCR thermal cycler (MP TP3000, Takara) as follows: 30 cycles of denaturation at $94^{\circ} \mathrm{C}$ for $1 \mathrm{~min}$, annealing at $60^{\circ} \mathrm{C}$ for $1 \mathrm{~min}$ and extension at $72^{\circ} \mathrm{C}$ for $1 \mathrm{~min}$ and then a final extension at $72^{\circ} \mathrm{C}$ for $3 \mathrm{~min}$. The predicated size of the PCR products for HGF and GAPDH were 447 and $983 \mathrm{bp}$, respectively. GAPDH amplification was used as an internal control to confirm that the samples contained similar amounts of cDNA. Amplified samples were visualised on agarose $2.0 \%$ gels stained with ethidium bromide and photographed under UV light. The bands of the photographs were scanned and then analysed with an ImageMaster 1D (Pharmacia Biotech, Uppsala, Sweden).

\section{Statistical analyses}

In most assays, the mean and SD were obtained, and the statistical significance of the difference between each test and its respective control was examined by Student's $t$ test. Most experiments were performed more than twice, and representative results are presented.

\section{Results}

$H G F / S F$ secretion from gingival fibroblasts stimulated with $P$. gingivalis whole cells

The study first examined the effects of $P$. gingivalis whole cells on the secretion of immunoreactive HGF/SF by human gingival fibroblasts. As shown in Fig. 1, P. gingivalis whole cells at $100 \mu \mathrm{g}$ (dry weight $/ \mathrm{ml}$ significantly stimulated the secretion of HGF/SF by the gingival fibroblasts. The HGF/SF level induced by the bacterial cells was similar to or stronger than that induced by the optimum concentration $(10 \mathrm{ng}$ of protein $/ \mathrm{ml}$ ) of the reference rHuIL- $1 \alpha$, although a higher concentration was required to exhibit activity for the bacterial cells.

\section{P. gingivalis fimbriae and LPS stimulate the secretion of $\mathrm{HGF} / \mathrm{SF}$ by fibroblasts}

P. gingivalis whole cells stimulated the production of HGF/SF by gingival fibroblasts. Therefore, the activities of representative cell-surface components of $P$. gingivalis, i.e., fimbriae and LPS - both of which are known to activate human gingival fibroblasts - were examined. As shown in Fig. 2, P. gingivalis fimbriae strongly stimulated the production of $\mathrm{HGF} / \mathrm{SF}$ by fibroblasts with a typical bell-shaped dose-response curve. HGF/SF production was increased from 10 to $100 \mu \mathrm{g}$ (protein) $/ \mathrm{ml}$ dose-dependently, then decreased to $1000 \mathrm{pg} / \mathrm{ml}$. The level of HGF/SF induced by fimbriae $100 \mu \mathrm{g} / \mathrm{ml}$ was more than two-fold higher than that induced by rHuIL- $1 \alpha 10 \mathrm{ng} / \mathrm{ml}$ LPS exhibited significant but weak activity. Total RNA was then extracted from gingival fibroblasts stimulated with $P$. gingivalis fimbriae or rHuIL-1 $\alpha$ and RT-PCR was performed to define the levels of HGF/SF mRNA. A definite band was observed in the gel containing RNA extracted from gingival fibroblasts stimulated with $P$. gingivalis fimbriae at $1-100 \mu \mathrm{g} / \mathrm{ml}$ (Fig. 3a). The results of ImageMaster 1D analysis indicated that the density of the bands increased in relation to the doses of fimbriae added and the band induced by $100 \mu \mathrm{g}$ of 


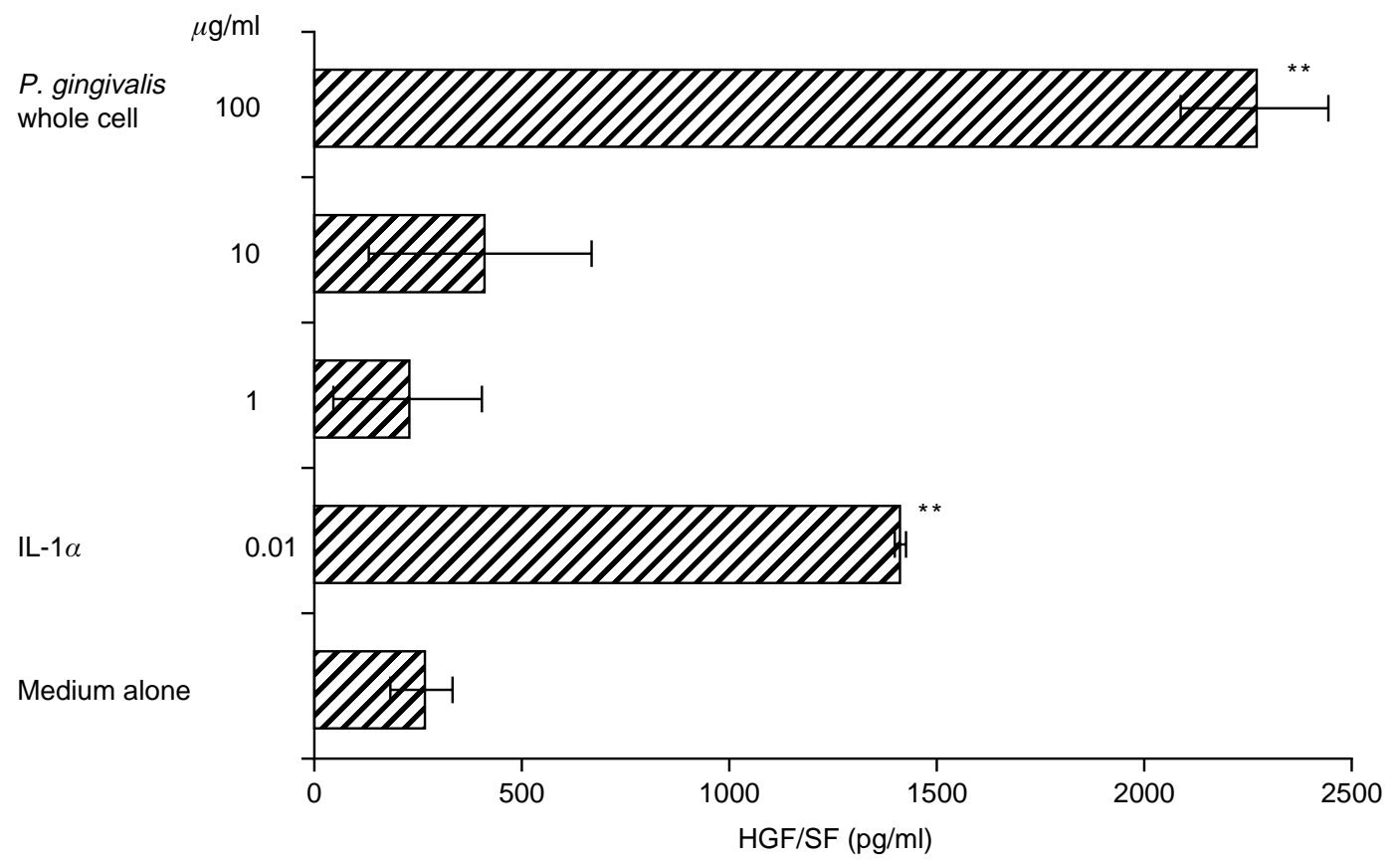

Fig. 1. HGF/SF secretion from human gingival fibroblasts stimulated with $P$. gingivalis whole cells. Fibroblasts were cultured at a density of $2.0 \times 10^{4}$ cells $/ 100 \mu \mathrm{l} /$ well in 96 -well plastic culture plates. Stimulants were added and incubated for $24 \mathrm{~h}$ in triplicate. Culture supernates were collected and the concentration of HGF/SF in the pooled specimens was determined by ELISA in triplicate assays. Values are means and SD. ${ }^{* *}$ Significantly different from the control (medium alone) as determined by Student's $t$ test $(\mathrm{p}<0.01)$. The results are representative of two different experiments.

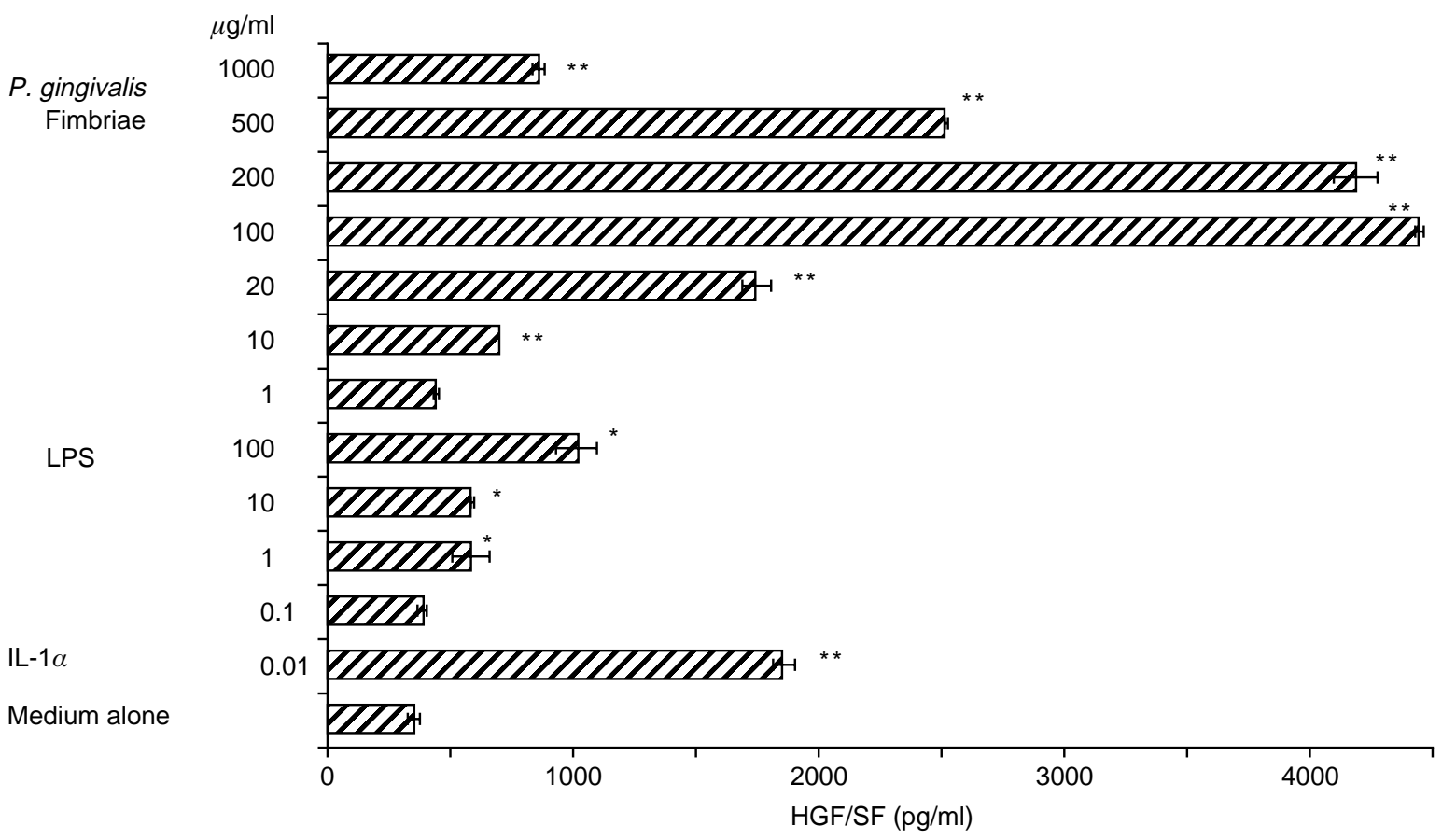

Fig. 2. HGF/SF secretion from human gingival fibroblasts stimulated with $P$. gingivalis fimbriae and LPS. Experimental conditions were the same as described in the legend to Fig. 1. Values significantly different from control are indicated: ${ }^{*} \mathrm{p}<0.05 ;{ }^{* *} \mathrm{p}<0.01$. The results are representative of three different experiments. 
a
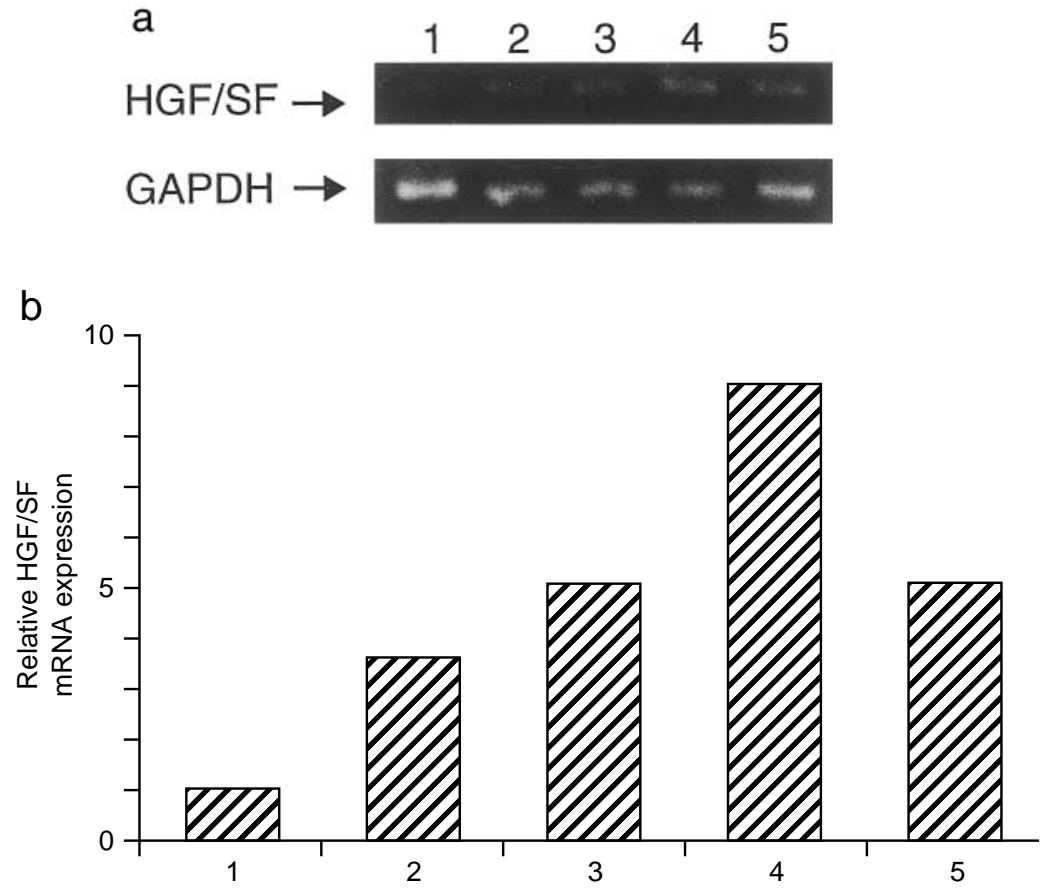

Fig. 3. Expression of $\mathrm{HGF} / \mathrm{SF} \mathrm{mRNA}$ in human gingival fibroblasts. Fibroblasts were stimulated with various concentrations of $P$. gingivalis fimbriae or reference rHuIL- $1 \alpha(10 \mathrm{ng} / \mathrm{ml})$ for $8 \mathrm{~h}$. Total RNA was extracted and RTPCR was carried out (a). Relative densities of the bands of HGF/SF mRNA shown in panel (a) were analysed with an ImageMaster 1D (b). Lane 1, medium alone; 2-4, P. gingivalis fimbriae (1, 10 and $100 \mu \mathrm{g} / \mathrm{ml}$, respectively); 5, rHuIL$1 \alpha(10 \mathrm{ng} / \mathrm{ml})$. The results are representative of two different experiments.

fimbriae/ml was about nine-fold denser than that induced by medium alone (Fig. 3b).

$H G F / S F$ production by gingival fibroblasts stimulated with synthetic peptides of fimbrial protein from $P$. gingivalis

Next, to elucidate the regions responsible for the HGF/SF-inducing activity of fimbriae, the study examined seven synthetic peptide segments of $P$. gingivalis fimbrial protein. The peptide FP381(302321) stimulated HGF/SF production by fibroblasts at concentrations of $10-1000 \mu \mathrm{g}$ (dry weight) $/ \mathrm{ml}$, although the activity was considerably weaker than that of reference rHuIL-1 $\alpha$ (Fig. 4). The peptide FP381(282-301) also exhibited weak activity at the highest concentration $(1000 \mu \mathrm{g} / \mathrm{ml})$. The other peptides showed no significant activity.

\section{Discussion}

This study found that $P$. gingivalis whole cells, fimbriae and LPS enhanced the production of $\mathrm{HGF} / \mathrm{SF}$ by human gingival fibroblasts in culture, and that the fimbriae exhibited the strongest $\mathrm{HGF} / \mathrm{SF}$-inducing activity reported to date. $P$. gingivalis fimbriae have been studied as a possible virulence factor of this bacterium in relation to periodontitis $[14,15]$. The fimbriae are involved in the adherence of the bacterium to host cells, especially to human gingival fibroblasts
$[18,32,33]$. The fimbriae also stimulate human gingival fibroblasts to increase the production of inflammatory cytokines such as IL-1 and IL-8 [18, 19]. Therefore, IL-1 produced by fibroblasts in response to the fimbriae might in turn induce $\mathrm{HGF} / \mathrm{SF}$ in the fibroblast cultures. However, the fimbriae should induce $\mathrm{HGF} / \mathrm{SF}$ directly in the fibroblast cultures, because peak HGF/SF mRNA expression was noted after cultivation of the fibroblasts with the fimbriae for several hours, at which time IL-1 had not yet been released from the fibroblasts (data not shown). Ogawa et al. [20] demonstrated the specific binding region within fimbrillin of $P$. gingivalis on to human gingival fibroblasts in terms of the antagonistic effect of synthetic peptides corresponding to various fimbrillin segments. The data obtained in the present study were in accordance with the results of Ogawa et al. [20]; the antagonistic peptides FP381(282-301) and FP381(302-321) exhibited a definite HGF/SF-inducing activity in this study, whereas FP381(81-101), FP381(142-161) and FP381(182-201) showed no significant activity in either assay. Comparable results were not available in the antagonistic assay for FP381(61-80) and FP381(216-241), both of which showed no significant activity in this study. It must be noted that the fibroblast-activating effect of the synthetic peptides required higher concentrations than those required for their antagonistic effects. Thus, the higher order structures of fimbrillin or fimbriae might be required to exert the stimulating activity efficiently, and the segment peptides may not be sufficient to exert the activity. 
Experiment 1

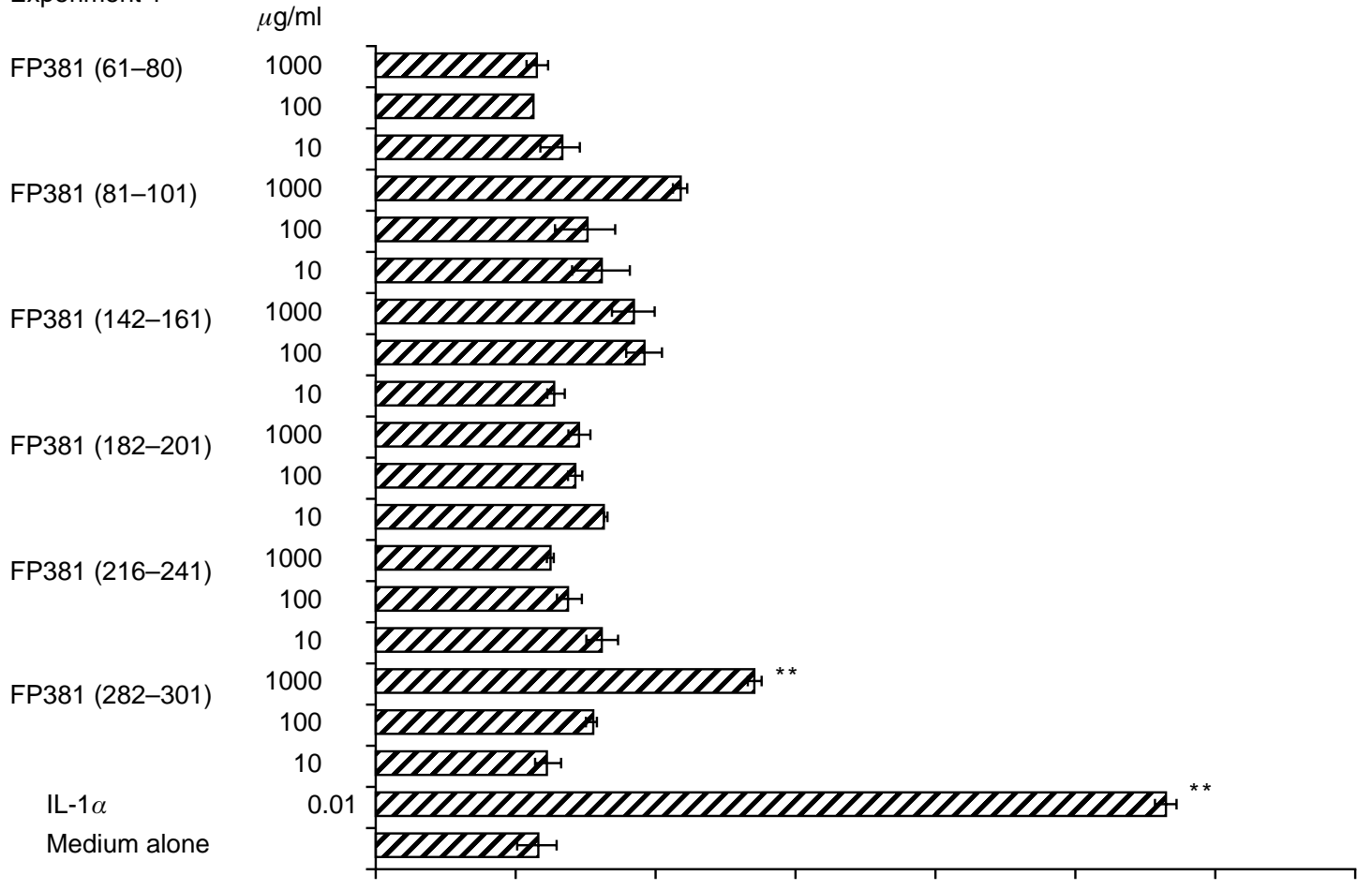

Experiment 2

FP381 (302-32

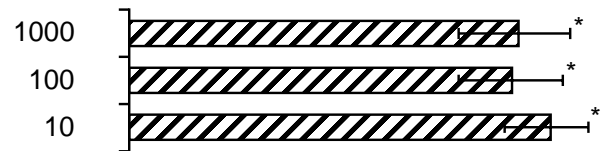

IL-1 $\alpha$

Medium alone

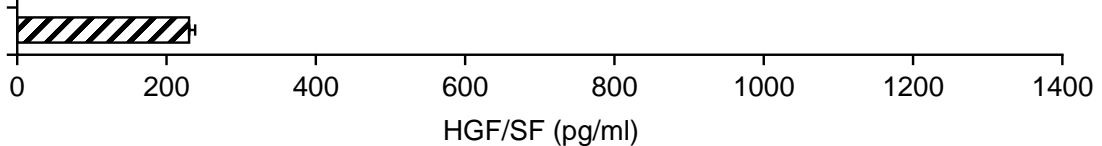

Fig. 4. HGF/SF secretion from human gingival fibroblasts stimulated with various synthetic peptides corresponding to the segments of $P$. gingivalis 381 fimbrillin. Experimental conditions were the same as described in the legend to Fig. 1. *, ** Significantly different from control $\left(* \mathrm{p}<0.05,{ }^{* *} \mathrm{p}<0.01\right)$.

A previous study reported that none of the LPS or lipid A specimens tested to date induced HGF/SF in human gingival fibroblasts in culture [10]. It must be emphasised that the inactivity of LPS (from Salmonella abortusequi) was confirmed both in high-CD14- expressing and low-CD14-expressing gingival fibroblasts (unpublished observations). Purified Pr. intermedia LPS was also inactive in this respect, although the crude LPS fraction extracted with hot phenol-water from the same bacterium exhibited definite HGF/SFinducing activity [9]. The HGF/SF-inducing activity of the LPS fraction might be attributable to a bioactive glycopeptide, PGP, which exerted powerful HGF/SFinducing activity [9]. There is a great deal of evidence suggesting similarities in the lipid A structures of $P$. gingivalis and Pr. intermedia [9, 16, 17]. Therefore, the activity of $P$. gingivalis LPS detected in the present study might also be attributable to the PGP-comparable minor component(s) in the LPS specimen. Another possibility is that the unique lipid A structure of the bacterium [34,35], which is capable of activating human gingival fibroblasts to produce IL-8 [19], stimulates the cells to produce $\mathrm{HGF} / \mathrm{SF}$ in a manner different from that of common LPS and lipid A.

P. gingivalis is the most widely studied periodontopathic bacterium [13]. Therefore, the HGF/SF induced by the bacterial components might have a role in some periodontal diseases. In fact, it has been suggested that $\mathrm{HGF} / \mathrm{SF}$ is responsible for osteoclast formation [12]. The HGF/SF receptor, c-Met, is expressed on both osteoclast-like cells and osteoblasts [11]. HGF/SF induces changes of shape and stimulates the chemotactic migration and proliferation of osteoclasts, and the cells then synthesise and secrete biologically active HGF/SF, suggesting the existence of autocrine and paracrine mechanisms of regulation of the osteoclasts and osteoblasts, respectively, by $\mathrm{HGF} / \mathrm{SF}$. The possible multiple functions of $\mathrm{HGF} / \mathrm{SF}$ in gingival epithelial cells and endothelial cells may be involved in both destructive and reparative phases in periodontal diseases under different physiological and pathological conditions. HGF/SF has been shown to induce blood vessel formation in vitro [36] and in vivo [37], and may be 
involved in tissue regeneration. At present, studies of $\mathrm{HGF} / \mathrm{SF}$ in relation to periodontal diseases are still in the initial stages, and further findings are eagerly awaited.

We thank D. Mrozek (Medical English Service, Kyoto, Japan) for reviewing this paper. This work was supported in part by Grants-inAid for Scientific Research (09671843 and 10470378) and a Grantin-Aid for Scientific Research on Priority Areas (Cancer) (07273108) from the Ministry of Education, Science, Sports, and Culture of Japan. A.S. was supported by a research fellowship from the Japan Society for the Promotion of Science for Young Scientists.

\section{References}

1. Gohda E, Tsubouchi H, Nakayama $\mathrm{H}$ et al. Purification and partial characterization of hepatocyte growth factor from plasma of a patient with fulminant hepatic failure. $J$ Clin Invest 1988; 81: 414-419.

2. Tsubouchi H, Gohda E, Strain AJ, Daikuhara Y. The role of HGF-SF in animal and human hepatic physiology and pathology. In: Goldberg ID, Rosen EM (eds) Hepatocyte growth factor-scatter factor (HGF-SF) and the c-Met receptor. (EXS 65) Basel, Birkhäuser Verlag. 1993: 251-274.

3. Weidner KM, Arakaki N, Hartmann G et al. Evidence for the identity of human scatter factor and human hepatocyte growth factor. Proc Natl Acad Sci USA 1991; 88: 7001-7005.

4. Gherardi E, Gray J, Stoker M, Perryman M, Furlong R. Purification of scatter factor, a fibroblast-derived basic protein that modulates epithelial interactions and movement. Proc Natl Acad Sci USA 1989; 86: 5844-5848.

5. Goldberg ID, Rosen EM (eds). Hepatocyte growth factorscatter factor (HGF-SF) and the c-Met receptor. (EXS 65) Basel, Birkhäuser Verlag. 1993.

6. Bottaro DP, Rubin JS, Faletto DL et al. Identification of the hepatocyte growth factor receptor as the c-met proto-oncogene product. Science 1991; 251: 802-804.

7. Naldini L, Weidner KM, Vigna E et al. Scatter factor and hepatocyte growth factor are indistinguishable ligands for the MET receptor EMBO J 1991; 10: 2867-2878.

8. Tamura M, Arakaki N, Tsuboushi H, Takada H, Daikuhara Y. Enhancement of human hepatocyte growth factor production by interleukin- $1 \alpha$ and $-1 \beta$ and tumor necrosis factor- $\alpha$ by fibroblasts in culture. J Biol Chem 1993; 268: 8140-8145.

9. Iki K, Kawahara K, Sawamura S et al. A novel component different from endotoxin extracted from Prevotella intermedia ATCC 25611 activates lymphoid cells from C3H/HeJ mice and gingival fibroblasts from humans. Infect Immun 1997; 65: 4531-4538.

10. Sugiyama A, Arakaki R, Ohnishi T, Arakaki N, Daikuhara Y, Takada H. Lipoteichoic acid and interleukin 1 stimulate synergistically production of hepatocyte growth factor (scatter factor) in human gingival fibroblasts in culture. Infect Immun 1996; 64: 1426-1431.

11. Grano M, Galimi F, Zambonin G et al. Hepatocyte growth factor is a coupling factor for osteoclasts and osteoblasts in vitro. Proc Natl Acad Sci USA 1996; 93: 7644-7648.

12. Sato $\mathrm{T}$, Hakeda $\mathrm{Y}$, Yamaguchi $\mathrm{Y}$ et al. Hepatocyte growth factor is involved in formation of osteoclast-like cells mediated by clonal stromal cells (MC3T3-G2/PA6). J Cell Physiol 1995; 164: 197-204.

13. Shah HN, Mayrand D, Genco RJ (eds). Biology of the species Porphyromonas gingivalis. Boca Raton, FL, CRC Press. 1993.

14. Genco RJ, Sojar H, Lee J-Y et al. Porphyromonas gingivalis fimbriae: structure, function, and insertional inactivation mutants. In: Genco R, Hamada S, Lehner T, McGhee J, Mergenhagen S (eds) Molecular pathogenesis of periodontal disease. Washington, DC, ASM Press. 1994: 13-23.

15. Hamada S, Fujiwara T, Morishima S et al. Molecular and immunological characterization of the fimbriae of Porphyromonas gingivalis. Microbiol Immunol 1994; 38: 921-930.

16. Hamada S, Takada H, Ogawa T, Fujiwara T, Mihara J. Lipopolysaccharides of oral anaerobes associated with chronic inflammation: chemical and immunomodulating properties. Int Rev Immunol 1990; 6: 247-261.

17. Wilson M. Biological activities of lipopolysaccharide and endotoxin. In: Shah HN, Mayrand D, Genco RJ (eds) Biology of the species Porphyromonas gingivalis. Boca Raton, FL, CRC Press. 1993: 171-197.

18. Hanazawa S, Hirose K, Ohmori Y, Amano S, Kitano S Bacteroides gingivalis fimbriae stimulate production of thymocyte-activating factor by human gingival fibroblasts. Infect Immun 1988; 56: 272-274.

19. Ogawa T, Ozaki A, Shimauchi H, Uchida H. Hyporesponsiveness of inflamed human gingival fibroblasts from patients with chronic periodontal diseases against cell surface components of Porphyromonas gingivalis. FEMS Immunol Med Microbiol 1997; 18: $17-30$.

20. Ogawa T, Ogo H, Kinoshita A. Antagonistic effect of synthetic peptides corresponding to the binding regions within fimbrial subunit protein from Porphyromonas gingivalis to human gingival fibroblasts. Vaccine 1997; 15: 230-236.

21. Takada H, Mihara J, Morisaki I, Hamada S. Induction of interleukin-1 and -6 in human gingival fibroblast cultures stimulated with Bacteroides lipopolysaccharides. Infect Immun 1991; 59: 295-301.

22. Tamura M, Tokuda M, Nagaoka S, Takada H. Lipopolysaccharides of Bacteroides intermedius (Prevotella intermedia) and Bacteroides (Porphyromonas) gingivalis induce interleukin-8 gene expression in human gingival fibroblast cultures. Infect Immun 1992; 60: 4932-4937.

23. Sugawara S, Sugiyama A, Nemoto E, Rikiishi H, Takada H Heterogenous expression and release of CD14 by human gingival fibroblasts: characterization and CD14-mediated interleukin-8 secretion in response to lipopolysaccharide. Infect Immun 1998; 66: 3043-3049.

24. Watanabe A, Takeshita A, Kitano S, Hanazawa S. CD14mediated signal pathway of Porphyromonas gingivalis lipopolysaccharide in human gingival fibroblasts. Infect Immun 1996; 64: 4488-4494.

25. Ogawa T, Shimauchi H, Hamada S. Mucosal and systemic immune responses in $\mathrm{BALB} / \mathrm{c}$ mice to Bacteroides gingivalis fimbriae administered orally. Infect Immun 1989; 57: 3466-3471.

26. Takada H, Hirai H, Fujiwara T, Koga T, Ogawa T, Hamada S. Bacteroides lipopolysaccharides (LPS) induce anaphylactoid and lethal reactions in LPS-responsive and -nonresponsive mice primed with muramyl dipeptide. J Infect Dis 1990; 162: 428434.

27. Dickinson DP, Kubiniec MA, Yoshimura F, Genco RJ Molecular cloning and sequencing of the gene encoding the fimbrial subunit protein of Bacteroides gingivalis. J Bacteriol 1988; 170: $1658-1665$

28. Ogawa T, Kusumoto Y, Uchida H, Nagashima S, Ogo H, Hamada S. Immunobiological activities of synthetic peptide segments of fimbrial protein from Porphyromonas gingivalis. Biochem Biophys Res Commun 1991; 180: 1335-1341.

29. Tsubouchi H, Niitani Y, Hirono S et al. Levels of the human hepatocyte growth factor in serum of patients with various liver diseases determined by an enzyme-linked immunosorbent assay. Hepatology 1991; 13: 1-5.

30. Miyazawa K, Tsubouchi H, Naka D et al. Molecular cloning and sequence analysis of cDNA for human hepatocyte growth factor. Biochem Biophys Res Commun 1989; 163: 967-973.

31. Tso JY, Sun X-H, Kao T, Reece KS, Wu R. Isolation and characterization of rat and human glyceraldehyde-3-phosphate dehydrogenase cDNAs: genomic complexity and molecular evolution of the gene. Nucleic Acids Res 1985; 13: 2485-2502.

32. Hamada N, Watanabe $\mathrm{K}$, Sasakawa C, Yoshikawa M, Yoshimura F, Umemoto T. Construction and characterization of a fimA mutant of Porphyromonas gingivalis. Infect Immun 1994; 62: 1696-1704.

33. Watanabe K, Yamaji Y, Umemoto T. Correlation between celladherent activity and surface structure in Porphyromonas gingivalis Oral Microbiol Immunol 1992; 7: 357-363.

34. Kumada H, Haishima Y, Umemoto T, Tanamoto K. Structural study on the free lipid A isolated from lipopolysaccharide of Porphyromonas gingivalis. J Bacteriol 1995; 177: 2098-2106.

35. Ogawa T. Chemical structure of lipid A from Porphyromonas (Bacteroides) gingivalis lipopolysaccharide. FEBS Lett 1993, 332: $197-201$.

36. Bussolino F, Di Renzo MF, Ziche M et al. Hepatocyte growth factor is a potent angiogenic factor which stimulates endothelial cell motility and growth. J Cell Biol 1992; 119: 629-641.

37. Grant DS, Kleinman HK, Goldberg ID et al. Scatter factor induces blood vessel formation in vivo. Proc Natl Acad Sci USA 1993; 90: 1937-1941. 